\title{
Large for Gestational Age
}

National Cancer Institute

\section{Source}

National Cancer Institute. Large for Gestational Age. NCI Thesaurus. Code C87092.

A fetus or infant who is larger than expected for the age or gender, or who has a birth weight greater than the 90th percentile. 